\title{
EXPERIMENTAL INVESTIGATION OF SAND MINIMUM TRANSPORT VELOCITY IN MULTIPHASE FLUID FLOW IN PIPES
}

\author{
K. Bello ${ }^{1}$, and B. Oyeneyin ${ }^{2}$ \\ ${ }^{1}$ Department of Petroleum EngineEring, University of Benin, Benin City, Edo State. NiGERia. \\ ${ }^{2}$ SCHOOL OF ENGINEERING, ROBERT GORDON UNIVERSITY, ABERDEEN, UNITED KINGDOM \\ E-mail addresses:1 belloko@uniben.edu, ${ }^{2}$ b.oyeneyin@rgu.ac.uk
}

\begin{abstract}
The production of reservoir fluid through long tiebacks/pipelines has emerged as one of the cost effective alternative especially for many marginal fields which can now be produced as clusters into a common processing facility. However, sand is often co-produced with the reservoir fluid especially when produced from unconsolidated formations. The sand will settle to form beds along the bottom of the pipe if the fluid velocity is below the minimum transport velocity required (MTV). In order to prevent solid deposition and ensure flow assurance, it is therefore critical to identify and measure the MTV. Two approaches are generally recognised for development of solid minimum transport velocity models in pipelines, the analytical and empirical methods. Because of the complexities of multiphase flow, the analytical approach will often require some assumptions and inputs from empirical measurement. This study presents the results of the experimental investigation for minimum transport velocity (MTV) both in suspension and rolling. The minimum transport velocity was found to be greatly influenced by the flow patterns and pipe inclinations. It was observed that the slug flow provides better solid carrying capacity in pipes when compared with other observed flow patterns. It was also observed that the influence of pipe inclination diminishes beyond $20^{\circ}$. The acquired experimental data will ultimately provide a comprehensive data base for testing and validations of analytical models for improved accuracy. The justification for experimental work was evident from the inconsistent and inaccurate results obtained using existing analytical models for MTV predictions.
\end{abstract}

Keywords: Multiphase Fluid, Flow Patterns, Sand Minimum Transport Velocity, Tiebacks, Empirical method, Suspension and Rolling

\section{INTRODUCTION}

The transportation of unprocessed multiphase reservoir fluid through long subsea tiebacks has generated significant research interest in recent times. The reservoir fluid comes along with entrained solids which may drop off and form bed in the low side of the pipeline as the flow pressure declines. In order to continuously transport this unprocessed multiphase fluids through a long subsea tiebacks without solid depositions, there is the need for proper understanding of the various multiphase flow patterns and how it affect solid transport. This among other factors will enable for the development of appropriate predictive models for solid transport either in suspension or rolling modes.

In the light of the above, there is need to acquire useful experimental data for model testing and validation of theoretical models. Falcone et al. [1] identified two niche areas of research such as sand transport in multiphase flows, the investigation of the dynamic interaction between flow in porous media and flow in pipes under transient flow conditions.

Two approaches are generally recognised for development of solid transport models in pipelines, the analytical and empirical methods. Because of the complexities of multiphase flow, the analytical approach will often require some assumptions and inputs from empirical measurement particularly when describing the interactions between fluids and particles. The combination of these approaches is believed to have better predictive tendency. This can be used to develop semi-empirical models for sand minimum transport velocity (MTV) in suspension and rolling. 
The minimum transport velocity, MTV for suspension is the velocity above which the mixture flows in asymmetric suspension pattern or the velocity below which solids form a deposit on the bottom of the pipe. The minimum transport velocity, MTV for rolling is the velocity at and above which a moving bed of particle exists on the bottom of the pipe and some particles move by saltation or the velocity below which the part of the bed in contact with the pipe wall becomes stationary.

In pipelines, three key sand flow patterns are generally identified. These are stationary bed, suspension (heterogeneous or homogeneous) and rolling or saltation [2-5]. The characterisation are often achieved by direct visual observation, video recording or with the aid of acoustic sand detection [3, 5-8].

The classifications of sand flow patterns reported in the literatures by other researchers are similar and can be distinctly classified as follows, $[9,10]$

- Homogeneous suspension: Sand is transported in suspension and distributed uniformly inside the pipe.

- Suspension/Saltation: Sand is still transported in suspension but it is densely populated near the low-side wall so that it is virtually transported by jumping forward or saltating on the surface of the low-side pipe wall.

- Continuous Moving Bed: A thin, continuous sand bed is formed on the low-side wall of the pipe with the sand near the low-side wall rolling or sliding forward at a lower velocity than that above the bed.

- Stationary Bed: A continuous sand bed is formed on the low-side wall of the pipe with the sand on the surface of the bed rolling or sliding forward whilst the sand inside the bed is stationary.

The attempt here was to investigate solid transport in a multiphase flow and transient phenomenon associated with water-gas-oil-solid flow in pipeline in a view to determine the MTV. This among other things was to provide insight into particle transport mechanisms and its motion in three/four phase flow system given the continuous changes in flow patterns associated with multiphase fluids. The design of a multiphase process flow loop for acquisition of multiphase flow patterns and MTV data was reported in [11]. The designed flow loop enabled acquisition of minimum transport velocity data for suspension and rolling given different scenarios of pipe sizes, pipe inclinations, solid concentrations and flow patterns.

\section{METHODOLOGY}

The sand transport experiments were conducted using three different fluid systems and two sand sample sizes. The concentrations of the sand samples including the fluid systems were varied for each experimental run. The flow rates were varied to determine the MTV for either suspension or rolling and for each of the pipe sizes. A combination of the fluid systems, water-oil-gas mixtures was used to create multiphase fluids. Different pipe orientations were used, the horizontal, vertical and inclined test sections. The diameters of horizontal and vertical test sections are 0.07 and 0.08 meters respectively. The inclined test section with pipe diameter of 0.1 meter was varied at three different angles, $15^{\circ}, 20^{\circ}$ and $25^{\circ}$.

The minimum transport velocity (MTV) was determined by visual method while the mixture is flowing in a transparent tubes for each of the experimental run. This relies upon identifying the exact flow rate at which the solid begin to drop out of the flowing fluid when initially in suspension, that is MTV for suspension. The exact flow rate when the solid begin to move when initially at rest was determined for MTV rolling. The minimum transport velocities (either for suspension or rolling) were determined by measuring the flow rates at which the particles begin to drop off or move from stationary.

Prior to each experimental run, a known quantity of sand particle was added to a known volume of water/liquid. The mixture was well agitated using a mixer mounted on top of the test tank. The mixture was pumped through the flow loop and rate measured either for suspension or rolling with the aid of a Doppler flow meter which was displayed on Lab View (digital data acquisition software). The water-sand mixture was then allowed to flow continuously through the test sections for about 10 minutes to ensure suspension homogeneity.

At the end of each experimental run, the sand particle was separated from mixture using a filter. The water is then re-circulated into the system continuously until all sand particles are recovered.

In order to ascertain level of attrition of the sand, a quick check of the sand distribution was carried out using sieve analysis method and compared with $d_{50}$ used for the experiment.

\section{RESULTS}

The MTV results for water-sand flow experiments are as presented in Figures 1 to 3. The sand was run with water alone in three different pipe sizes; the measured 
velocities are remarkably different for suspension and rolling as shown in Figure 1. It can be seen that, the velocity required to initiate sand rolling is less than that to maintain solid particle in suspension. The pipe diameter also affects MTV to a reasonable extent. Figures 2 and 3 are results for MTV suspension and rolling given different sand concentration profiles. For MTV rolling, no significant change was observed when the sand concentration was changed from $1.9 \%$ to $2.5 \%$. However, there was significant change in measured MTV for suspension when sand concentration was increased.

For lower sand concentrations, transportation mechanism will be enhanced and will require less energy. The two sand concentrations investigated for the same particle size both in horizontal and inclined test sections clearly showed the significant effects of sand loading with respect to flow rates on sand transportation patterns in water-gas flow. The $d_{50}$ used in this experiment, 250-300 microns is a representative of the particle size commonly found in oil and gas production pipelines [12].

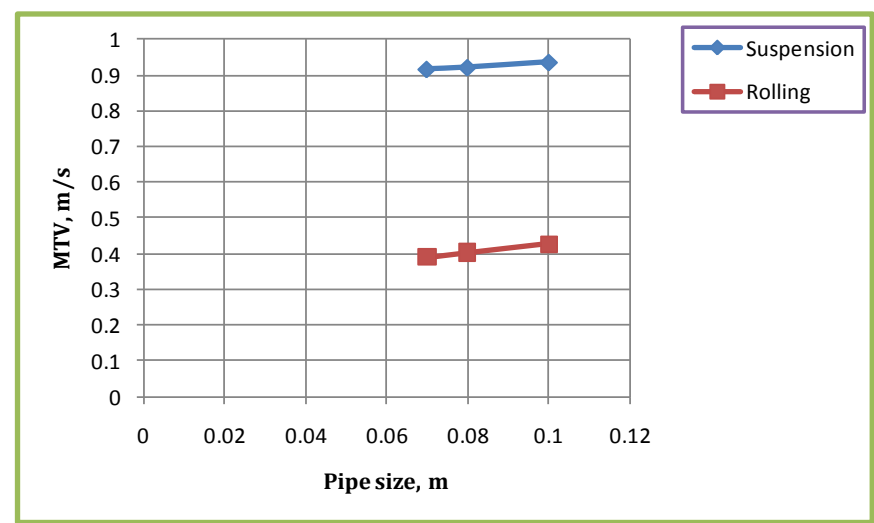

Figure 1: MTV for suspension and rolling in water-sand flow, $0.07 \mathrm{~m}, 0.08$ and $0.1 \mathrm{~m}$ pipe sizes. The $0.07 \mathrm{~m} \& 0.08 \mathrm{~m}$ are horizontal and $0.1 \mathrm{~m}$ pipe at $15^{\circ}$

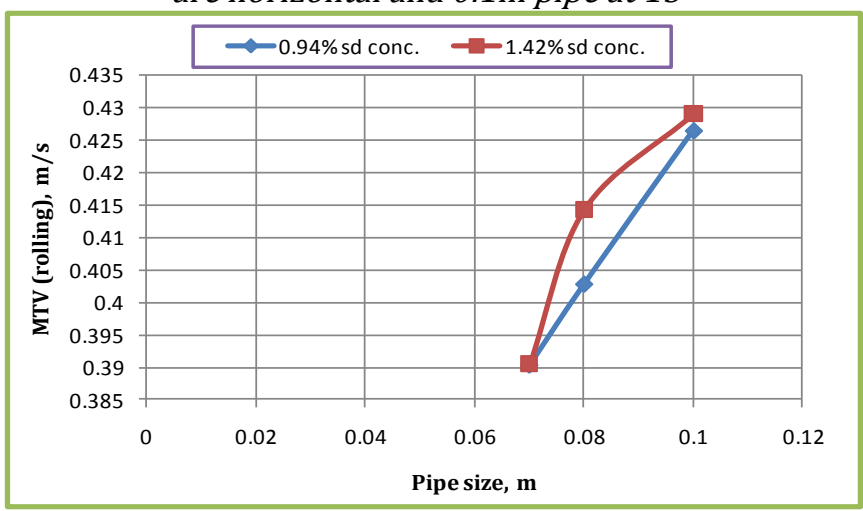

Figure 3: MTV for rolling in water-sand flow with different pipe sizes and sand concentrations. The $0.07 \mathrm{~m} \&$ $0.08 \mathrm{~m}$ are horizontal and $0.1 \mathrm{~m}$ pipe at $25^{\circ}$

\section{EFFECT OF GAS INJECTION ON MTV}

The effect of superficial gas velocity, Vsg on the fluid capacity to transport sand particle was studied. Figures $4 \& 5$ illustrate significant influence of superficial gas velocity on sand particle movement. The observed MTV may have been influenced by characteristics of the changes in flow patterns. The gradual increase in gas flow rates led to formation of dispersed bubbles which initiated strong turbulence and vortex formation in the pipe flow. This was a common scene in the $0.1 \mathrm{~m}$ inclined pipe as was discussed earlier. With further increase in gas flow rates, there was transition to stratified wavy and stratified smooth in 0.07 meter \& 0.08 meter horizontal pipes. It was observed that the fluid mixture has less capacity to transport the solid and increasingly the sand bed begin to form. In contrast, for 0.1 meter inclined pipe where slug flow developed there was enhanced solid transportation in the pipe which resulted in lower sand hold up. This phenomenon was also observed by previous investigators such as $[3,10]$.

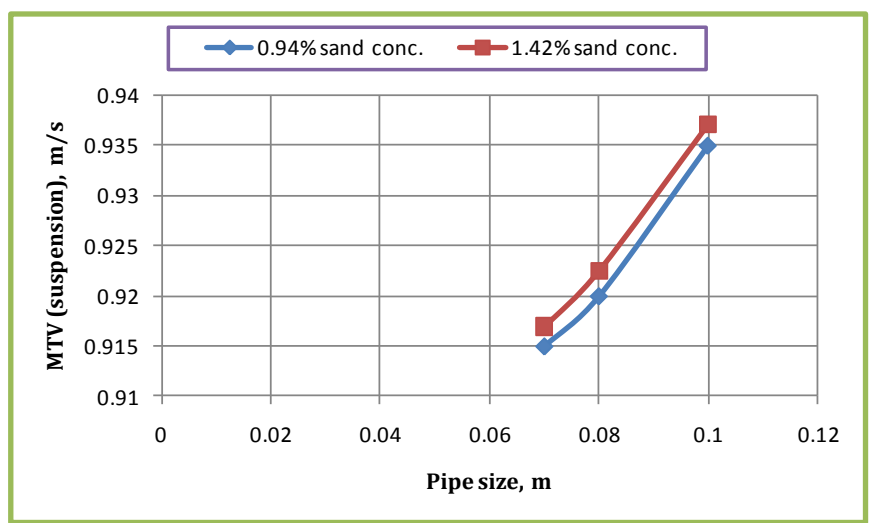

Figure 2: MTV for suspension in water-sand flow with different pipe sizes and sand concentrations. The $0.07 \mathrm{~m} \&$ $0.08 \mathrm{~m}$ are horizontal and $0.1 \mathrm{~m}$ pipe at $15^{\circ}$

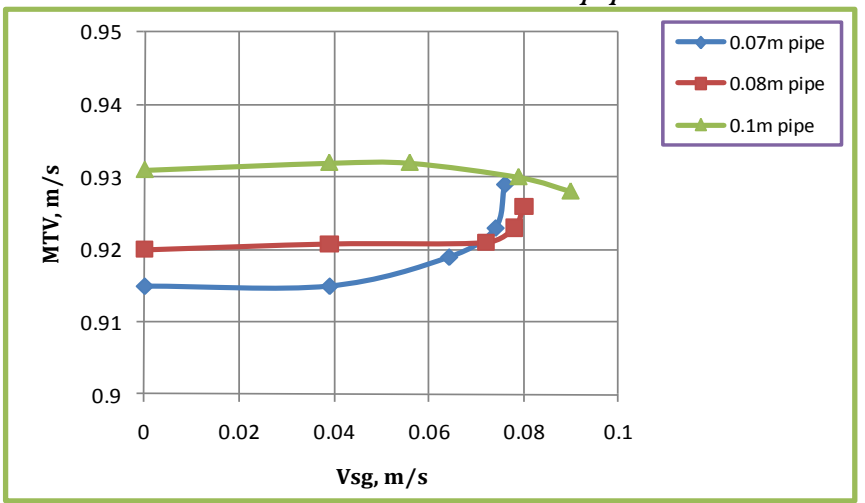

Figure 4: MTV suspension in water-gas-sand flow for different pipe sizes. The $0.07 \mathrm{~m} \& 0.08 \mathrm{~m}$ are horizontal and $0.1 \mathrm{~m}$ pipe at $15^{\circ}$ 


\subsection{Effect of Flow Patterns on MTV}

Figures $6 \& 7$ shows the results of the experiments on the effects of flow patterns on sand particle transport velocity profiles in horizontal \& inclined test pipe sections for water-oil-gas-sand flow systems. The flow pattern in 0.1 meter pipe section was predominantly slug flow as compared to the stratified and elongated bubble flow patterns in 0.07 meter $\& 0.08$ meter pipe sections respectively. Generally, there was decrease in sand deposition for all the three flow patterns. The greatest observable reduction in sand deposition was in slug flow, followed by elongated bubble flow and stratified flow patterns. The particle transport enhancement in slug flow can be attributed to the significant turbulent nature of the slug nose [13].

\subsection{Effect of Pipe Angle/Inclination on MTV}

The effect of angle of inclination on MTV was studied as shown in Figures $8-10$. The expectation will be that increasing the angle of inclination will require higher MTV. Because increasing the angle of inclination requires a higher driving force for the solid

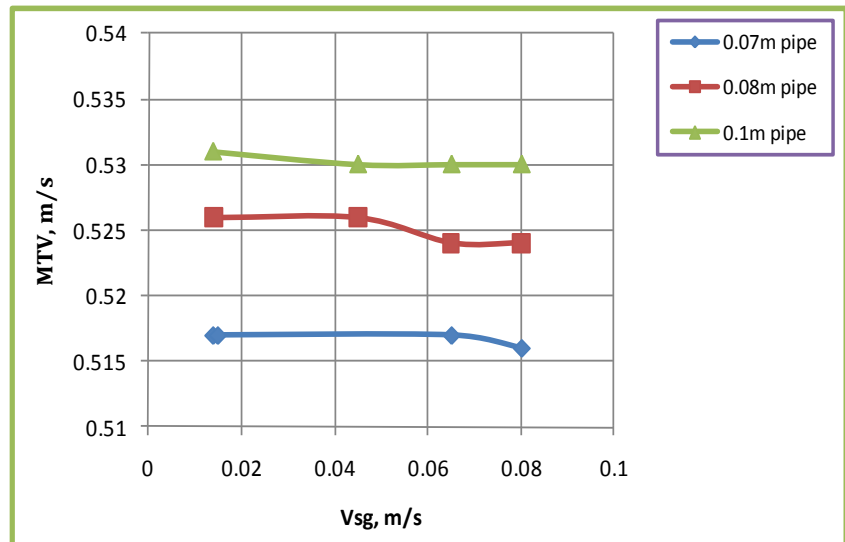

Figure 5: MTV rolling in water-gas-sand flow for different pipe sizes. The $0.07 \mathrm{~m} \& 0.08 \mathrm{~m}$ are horizontal and $0.1 \mathrm{~m}$ pipe at $15^{\circ}$

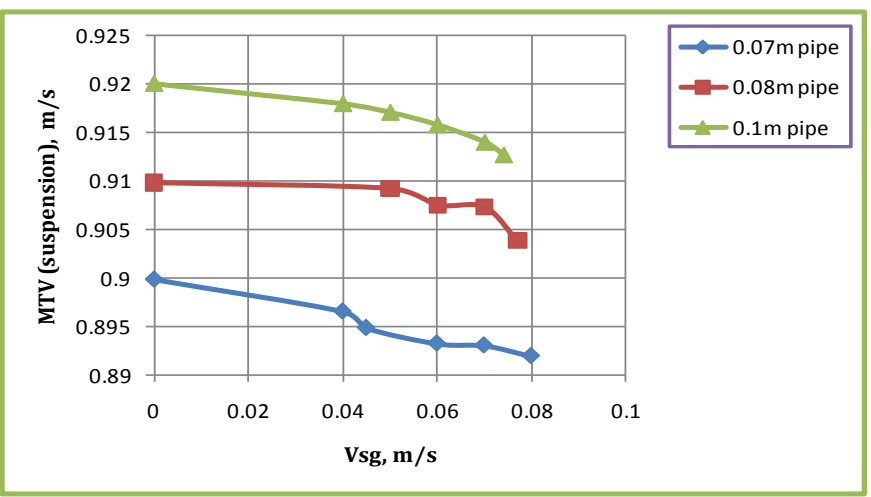

Figure 7: Effect of flow patterns on MTV in water-oil-gassand flow with $5 \%$ oil concentration. The $0.07 \mathrm{~m} \& 0.08 \mathrm{~m}$ pipe sizes are horizontal and $0.1 \mathrm{~m}$ pipe size inclined at $15^{\circ}$ particles coupled with the additional effect of the gravitational force should normally result in high MTV. However, reduction in MTV was observed which in this case was attributed to formation of slug flow. At higher inclinations, around $20^{\circ}-40^{\circ}$, depending on the operational conditions the limit deposit velocity passes through a maximum and then decreases at a moderate rate [14].

At various superficial velocities, it was observed that improved sand transport occurred primarily in the slug flow region with increased inclination as can be seen in Figures 8 - 10. When compared with horizontal pipe case, pipe inclinations contributed to formation of slug flow patterns for various superficial velocities used in this experiment. As the pipe angle was adjusted to $15^{\circ} \& 20^{\circ}$, there was apparent transition from disperse bubble flow to slug and this pattern is often characterised by lower MTV. Beyond $20^{\circ}$, minimal changes in MTV for suspension was observed, that is when pipe angle was adjusted to $25^{\circ}$, as shown in Figures 8 - 10.

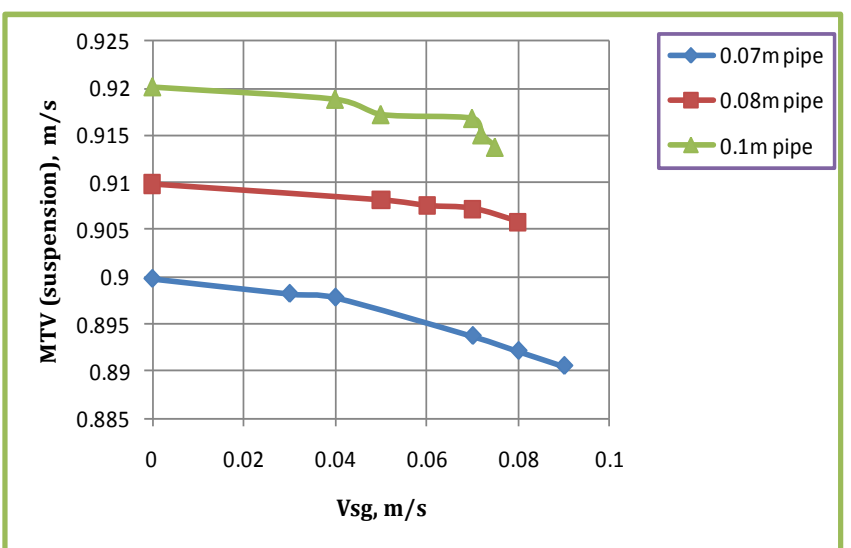

Figure 6: Effect of flow patterns on MTV in water-oil-gassand flow with $10 \%$ oil concentration. The $0.07 \mathrm{~m} \&$ $0.08 \mathrm{~m}$ pipe sizes are horizontal and $0.1 \mathrm{~m}$ pipe size inclined at $15^{\circ}$.

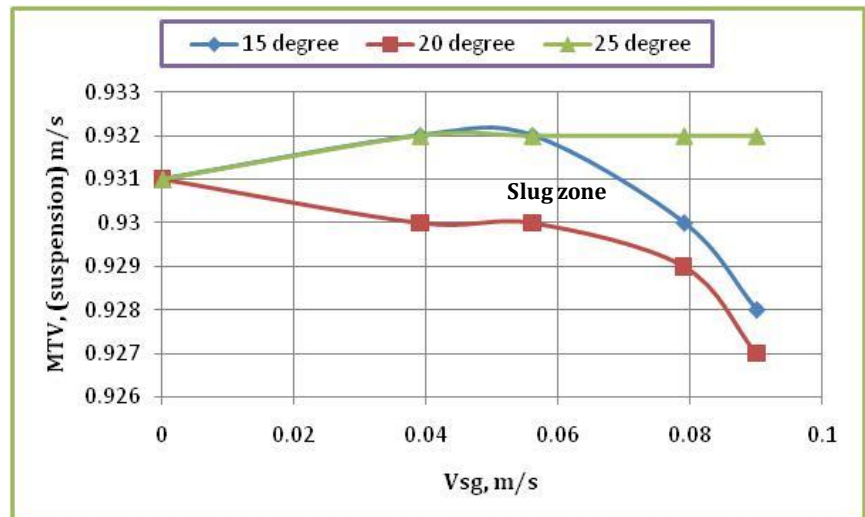

Figure 8: Effect of pipe angle and flow patterns on MTV for water-gas-sand flow in $0.1 \mathrm{~m}$ pipe size. 


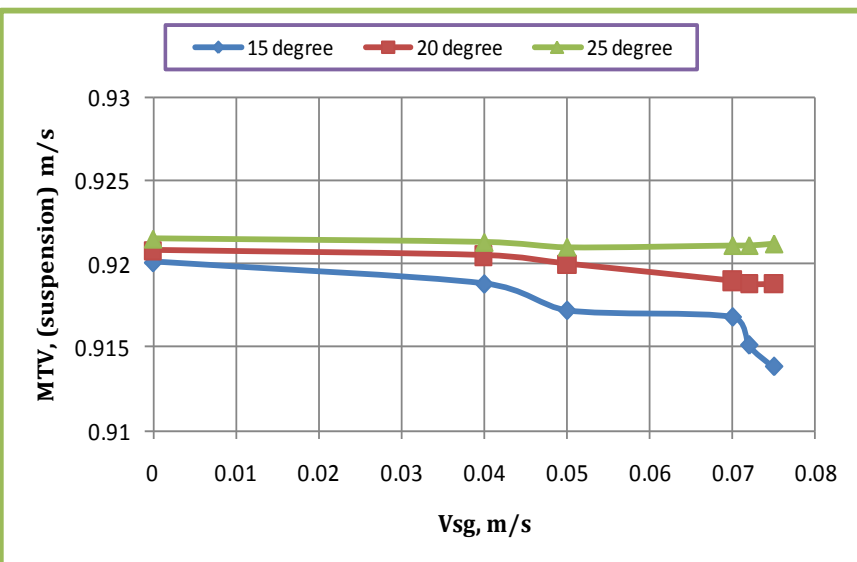

Figure 9: Effect of pipe angle and flow patterns on MTV for water-oil-gas-sand flow (10\% oil by volume, $0.1 \mathrm{~m}$ pipe)

This indicated that the change in pipe inclinations affects the flow patterns and consequently the MTV required for sand particle transport. Stevenson [12]argued that the impact of slug flow on solid particle transport is better appreciated on arrival of the turbulent core of the slug. It was obvious from the experiment that the slug flow played significant role in the transportation of solid particles in pipes caused by the change in pipe angles. It was also noted that as the inclination increases, the slug flow transited to elongated bubble flow which resulted in increased MTV and the effect of angle diminished.

\section{CONCLUSIONS}

The key observations from the experiments carried out are the following

- The minimum transport velocity (MTV) has been determined both in suspension and rolling modes. It was found to be greatly influenced by the flow patterns.

- The slug flow pattern provided better solid carrying capacity in pipes. For large pipe size, especially 0.1 meter pipe, there was tendency for flow patterns transiting directly from disperse bubble flow into slug flow or elongated bubble flow with slight change in flow conditions.

- The MTV required for transporting solid particle either in suspension or rolling is greatly influenced by pipe inclination of up to $20^{\circ}$ and the influence of angle appears to be diminishing beyond that.

- It was found that the solid particle concentration influence deposition either with water flowing or water-oil-gas flow.

- Expectedly, it was found that solid particle suspension is strongly dependent on the intensity

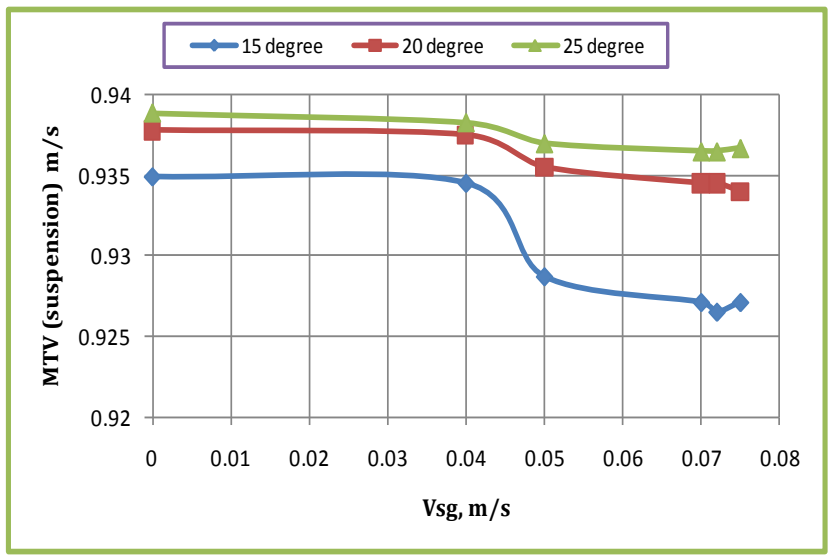

Figure 10: Effect of pipe angle and flow patterns on MTV for water-oil-gas-sand flow ( $5 \%$ oil by volume, $0.1 \mathrm{~m}$ pipe)

of fluid velocity in pipes irrespective of angle of inclination.

Most importantly, the comprehensive experimental work has provided a data base in multiphase sand transport flow in pipeline. This was a valuable measured data which will potentially serve as input parameters in the development and validation of minimum transport velocity models. This will be significant in the development of true and accurate models as many of the existing models relied on simulated data for development of sand transport models.

\section{REFERENCES}

1. Falcone, G., Teodoriu, C., Reinicke, K.M. and Bello, 0. O. "Multiphase Flow Modelling Based on Experimental Testing: An Overview of Research Facilities Worldwide and the Need for Future Development." Annual Technical Conference and Exhibition. November, 2007. California, USA: SPE.

2. Darby, R. Chemical Engineering Fluid Mechanics. Second ed. New York, USA: Marcel Dekker, Inc., 2001.

3. Oudeman, P. "Sand Transport and Deposition in Horizontal Multiphase Trunk lines of Subsea Satellite Developments". SPE Production \& Facilities, 1993.

4. Doron, P. and Barnea, D. "Flow Patterns Maps for Solid-Liquid Flow in Pipes". International Journal of Multiphase Flow, 22, 1996, pp. 273-283

5. Takahashi, H., Masuyama, T. and Noda, K. "Unstable Flow of a Solid - Liquid Mixture in a Horizontal Pipe". International Journal of Multiphase Flow, 15(5), 1989, pp. 831-841.

6. Salama, M. M. "Sand Production Management". Journal of Energy Resources, 122, 2000, pp. 29-33

7. Doron, P., Granica, D.and Barnea, D. "Slurry Flow in Horizontal Pipes - Experimental and Modelling. 
International Journal of Multiphase Flow, 13(4), pp. 535-547

8. Gilles, R. G., McKibben, M. J. and Shook, C. A. "Pipeline Flow of Gas, Liquid and Sand Mixtures at Low Velocities". The Journal of Canadian Petroleum Technology, 1997, 36(9).

9. Ford, J. T., Peden, J. M., Oyeneyin, M. B., Gao, E. and Zarrough, R. "Experimental Investigation of Drilled Cuttings Transport in Inclined Boreholes". Annual Technical Conference and Exhibition of the Society of Petroleum Engineers. September, New Orleans, USA, 1990, pp. 197-206

10.Danielson, T. J. "Sand Transport Modelling in Multiphase Pipelines". Offshore Technology Conference, SPE, Houston, USA. May, 2007.
11.Bello, K. O. and Oyeneyin, M. B. "Multiphase Flow Loop Design: Understanding Complexities of Multiphase Flow in Pipeline". Journal of Engineering for Development, 2013, Vol. 10.

12.Steveson, P. "The Transport of Particles at Low Loading in Near-Horizontal Pipes by Intermittent Flow". Chemical Engineering Science, 56, 2001, pp. 2149-2159

13.King, M. J. S., Fairhurst, C. P. and Hill, T. J. "Solid Transport in Multiphase Flows - Application to High Viscosity Systems". Transaction of ASME, 123, 2001, pp. 200-204

14. Doron, P., Simkhis, M. and Barnea, D. "Flow of Solid-Liquid Mixtures in Inclined Pipes". International Journal of Multiphase Flow, 23(2), 1997, pp. 313-323. 